\title{
Toxicity of Binary Mixtures of Phenol, Zinc and Cadmium to Yeast Strains Isolated from Hydrocarbon Impacted Soil
}

\author{
O. R. Nlemolisa ${ }^{1}$, C. E. Nwanyanwu ${ }^{1}$, C. O. Akujobi ${ }^{1}$, F. C. Ihenetu ${ }^{2}$, R. C. Nwokorie ${ }^{1}$, C. C. Obasi ${ }^{3}$, \\ U. N. Kemka', K. H. Uzoho' ${ }^{1}$, M. C. Nwoke ${ }^{4}$
}

${ }^{1}$ Department of Microbiology, Federal University of Technology, Owerri, Nigeria

${ }^{2}$ Department of Microbiology, Imo State University, Owerri, Nigeria

${ }^{3}$ Department of Public Health, Imo State University Owerri, Nigeria

${ }^{4}$ Department of Animal and Environmental Biology, Imo State University, Owerri, Nigeria

Email: ihenetufrancis@gmail.com

How to cite this paper: Nlemolisa, O.R., Nwanyanwu, C.E., Akujobi, C.O., Ihenetu, F.C., Nwokorie, R.C., Obasi, C.C., Kemka, U.N., Uzoho, K.H. and Nwoke, M.C. (2020) Toxicity of Binary Mixtures of Phenol, Zinc and Cadmium to Yeast Strains Isolated from Hydrocarbon Impacted Soil. Open Access Library Journal, 7: e6201.

https://doi.org/10.4236/oalib.1106201

Received: March 1, 2020

Accepted: April 20, 2020

Published: April 23, 2020

Copyright (๑) 2020 by author(s) and Open Access Library Inc.

This work is licensed under the Creative Commons Attribution International License (CC BY 4.0).

http://creativecommons.org/licenses/by/4.0/

\section{(c) (i) Open Access}

\begin{abstract}
Toxicity of zinc, cadmium and phenol and their binary mixtures were determined based on inhibition of dehydrogenase activities of yeasts strains isolated from hydrocarbon impacted soil. The yeasts isolated from the hydrocarbon impacted soil were identified as Saprochaete sp. and Cryptococcus sp. The toxicity of chemicals and their mixtures were evaluated in the concentration range of $0-16 \mathrm{mM}$ for phenol, $0-5 \mathrm{mM}$ for zinc and $0-0.4 \mathrm{mM}$ for cadmium. The binary mixture ratios were evaluated. The toxicity thresholds $\left(\mathrm{IC}_{50}\right)$ were estimated using 3-parameter logistic dose-response model. The $\mathrm{IC}_{50}$ shows that cadmium has the highest toxic effect on the yeasts with $\mathrm{IC}_{50}$ value of $0.075 \mathrm{mM}$ for Saprochaete sp. and $0.09 \mathrm{mM}$ for Cryptococcus sp. The binary toxicity of the mixtures on the enzyme activity of the yeasts was evaluated with toxic index (TI) model. Modulation of the toxic interactions by the components of the mixtures through synergistic, additive and antagonistic interactions on the heavy metals and phenol were possible against the dehydrogenase activity of the yeasts. However, the toxic effects of phenol and heavy metals would depend on their relative amount present in the environment.
\end{abstract}

\section{Subject Areas}

Analytical Chemistry, Environmental Chemistry, Metal Material

\section{Keywords}

Mixture, Toxicity, Yeast, Hydrocarbon 


\section{Introduction}

With the growth of industry, there has been a considerable increase in the discharge of industrial waste to the environment, chiefly soil and water, which has led to the accumulation of pollutants and heavy metals. The industrial effluents usually consist of a number of contaminants in varying concentrations which are generally harmful to the environment and living things. Among those pollutants, phenolic compounds pose a threat to the environment because of its toxicity and stability of bioaccumulation [1]. They are considered as one of the priority pollutants by the Environmental Protection Agencies [2] [3].

Phenol is one of the major toxic aromatic compounds being discharges from industry and enters into the natural ecosystem. Phenol and phenol derivatives are released from petrochemical, chemical, pharmaceuticals, wood processing plants, paper and pulp, coke manufacturing and pesticide industries. Phenol is included as one of the most hazardous pollutants in the list of Environmental Protection Agency (EPA) [4].

The indiscriminate release of heavy metals into the soil and waters is a major health concern worldwide, as they cannot be broken down to non-toxic forms and therefore have long-lasting effects on the ecosystem. Many of them are toxic even at very low concentrations. Heavy metals such as arsenic, cadmium, chromium, copper, lead, mercury, nickel, selenium, silver, zinc etc. are not only cytotoxic but also carcinogenic and mutagenic in nature [5]. Heavy metals can be group into essential metals such as copper, manganese, zinc, and iron, and nonessential metals such as cadmium, lead, mercury, and nickel [6]. Cadmium and lead are included among the major pollutants because of their high toxicity [7] [8] [9]. Cadmium is released to ecosystem by mine tailing, effluents from textile, leather, tannery, electroplating and galvanizing industries, as well as cadmium batteries.

Enzymes are referred to as markers of soil purity. Dehydrogenase enzyme is an indicator of total physiological activity of microorganism, because it occurs intercellularlly in all living microbial cells and it is connected with oxido processes in microorganisms [10] by transferring protons and electrons from substrates to acceptors in an electron transport system. Reduction of 2, 3, 5-triphenyltetrazolium chloride (TTC)-an indicator dye by microbial dehydrogenases [11] is a measure of microbial growth or viability in the presence or absence of toxicant. Bacteria play important role in the maintenance of natural ecosystems. Determination of the effects of toxic chemicals to bacteria serves as important criteria for the environmental risk assessment of chemicals of microbial growth or viability in the presence or absence of toxicant. Bacteria play important role in the maintenance of natural ecosystems.

Toxicological studies have provided good knowledge through which rules and regulations for management of chemicals have been drawn. In a polluted environment, whether aquatic or terrestrial, pollutants occur as mixtures and various interactions can take place during exposure of organisms to mixtures of pollutants. The interactions include additivity, synergism, orantagonism [12]. 
This study was carried out to evaluate the toxicity of mixtures of phenol, zinc and cadmium via dehydrogenase enzyme activities to yeast strains.

\section{Materials and Method}

\subsection{Study Area}

Orji mechanic village was situated in Orji, Owerri North Local Government Area of Imo State. It was occupied by auto mechanics in 1987. Geographically, the area falls between coordinates of latitude $5.24-5.27^{\circ} \mathrm{N}$ and longitude 7.04 $7.06^{\circ} \mathrm{E}$ with an area of $0.41 \mathrm{~km}^{2}$ and lying on an area of flat agricultural land converted to mechanic workshops and residential homes. The geology of the area consists of plain soil which is about $0.05-2.0 \mathrm{~mm}$ in size. The major activity in the site was basically repairs and maintenance of automobile vehicles.

\subsection{Sample Collection}

Petroleum products contaminated soil sample was collected using a sterile metal cylindrical tool at a depth of $5 \mathrm{~cm}$ below the soil surface. The sample was transferred into a sterile polyethylene bag and was immediately delivered to the laboratory for physicochemical analysis. $\mathrm{pH}$, total hydrocarbon (THC) was determined following the standard procedures [13]. Calcium (Ca) and magnesium $(\mathrm{Mg})$ were determined by EDTA titration while potassium $(\mathrm{K})$ and sodium $(\mathrm{Na})$ were determined by flame photometry. The percent organic matter (\%OM) was calculated from the percent organic carbon (\%OC) measured using Walker-Black [14] wet oxidation method. Total nitrogen (TN) was determined using the modified Kjeldahl distillation methods [15], while Lead $(\mathrm{Pb})$, Zinc $(\mathrm{Zn})$, Copper $(\mathrm{Cu})$ and Cadmium were determined by atomic absorption spectrophotometer (Perkins Elmer 3110) respectively.

\subsection{Isolation and Enumeration of Microorganisms}

Ten (10) fold serial dilution of the sample was prepared by weighing out $1 \mathrm{~g}$ of the soil sample and suspended into $10 \mathrm{ml}$ of sterile distilled water to form the stock. The mixture was stirred for $1 \mathrm{~min}$ in order to allow detachment of microbial cells from the soil particle. Using a sterile pipette, one militer $(1.0 \mathrm{ml})$ of the solution was serially diluted in saline solution contained in $20 \mathrm{ml}$ glass screw capped test tubes up to $10^{-8}$. Thereafter, an aliquot $(0.1 \mathrm{ml})$ of the dilutions $10^{-7}$ were plated out in triplicates on Potato Dextrose Agar (PDA) supplemented with $50 \mu \mathrm{g} / \mathrm{ml}$ of streptomycin antibiotic solution and $2 \mathrm{mM}$ of phenol [16], nutrient agar supplemented with $50 \mu \mathrm{g} / \mathrm{ml}$ of ketoconazole, and nutrient agar plate without supplements respectively. The plates were then incubated at $30^{\circ} \mathrm{C}$ for $48 \mathrm{~h}$. The colonies formed on each plate were enumerated and recorded as colony forming units per gram (cfu/g) of the soil sample.

\subsection{Screening for Selection of the Best Performing Organisms}

After incubation, the best performing organisms were selected by adding a drop 
of $0.1 \% 2,3,5$-triphenyltetrazolium chloride (TTC). The organisms that degraded TTC by turning red were selected.

\subsection{Purification of Isolate}

Two distinctive colonies that degraded TTC were picked and labeled as BRW and SRM respectively. They were subcultured onto PDA and the plates were incubated for $48 \mathrm{~h}$ at $30^{\circ} \mathrm{C}$. The purified isolates were sub cultured into nutrient agar slant and stored in a refrigerator at $4^{\circ} \mathrm{C}$ for identification and further test.

\subsection{Identification of Yeast Strains}

Morphologically distinct yeast colonies that developed on potato dextrose agar supplemented with phenol were purified on nutrient agar and identified based on morphological, microscopy and biochemical (Assimilation and Fermentation) characteristics according to Campbell et al., [17].

\subsection{Preparation of Inoculum}

The selected isolates were grown in $50 \mathrm{ml}$ of sterile nutrient broth medium and were incubated on a rotary shaker $(150 \mathrm{rpm})$ incubator for $48 \mathrm{~h}$ at room temperature $\left(28^{\circ} \mathrm{C} \pm 2^{\circ} \mathrm{C}\right)$. Thereafter, the cells were harvested by centrifugation (ALPIN MEDICAL ENGLAND90 (1)) at $6000 \mathrm{rpm}$ for 10 mins. The harvested cells were washed twice in sterile distilled water to ensure that there are no leftover of nutrient broth. The washed cells were suspended in nutrient broth and the optical density (OD) adjusted to 0.2 at wavelength of $600 \mathrm{~nm}$ using spectrophotometer (VIS spectrophotometer 721D, Life Assistance Scientific INST. CO).

\subsection{Test Chemicals}

The test chemicals and reagents used for the bioassay were analytical grades. The heavy metals used in the assay were $\mathrm{Zinc}\left(\mathrm{Zn}^{+2}\right)$ and Cadmium $\left(\mathrm{Cd}^{+2}\right)$ as $\mathrm{ZnSO}_{4} \cdot 6 \mathrm{H}_{2} \mathrm{O}$ and $\mathrm{CdSO}_{4}$ respectively. Phenol used was obtained from Sigma-chemical Co. USA. Stock concentrations $(10 \mathrm{mM})$ of zinc and cadmium were used for the assay, while $100 \mathrm{mM}$ was used for phenol.

\subsection{Design of Experiment}

Binary mixtures of phenol, zinc and cadmium were evaluated using fixed ratio rays experimental design. In each case, the mixture ratio is kept constant, while the total concentration of the mixture is varied to obtain a complete dose response relationship of the mixtures. The components of each of the binary mixture ratios studied were 5.9\%Zinc + 94.1\%Phenol, 20\%Zinc $+80 \%$ Phenol, $27.3 \%$ Zinc + 72.7\% Phenol, 50\%Zinc + 50\%Phenol, 66.6\%Zinc + 33.3\%Cadmium, 88.8\%Zinc + 11.2\%Cadmium, 92.3\%Zinc + 7.7\%Cadmium, 75\%Zinc + 25\%Cadmium .

\subsection{Dehydrogenase Activity Assay}

Dehydrogenase activity inhibition was determined using 2, 3, 5-triphenyltetrazolium chloride (TTC) as the artificial electron acceptor which was reduced to the 
red-coloured triphenylformazan (TPF). The inhibition assessment of dehydrogenase activity was done in $2 \mathrm{ml}$ volume of nutrient broth (pH7) and TTC supplemented with varying concentrations of zinc, phenol and cadmium or their mixtures. A $0.5 \mathrm{ml}$ portion of $\mathrm{x} 4$-strength $(0.2 \%)$ nutrient broth and required volumes of sterile distilled water and stock solution (10 mM for zinc and cadmium and $100 \mathrm{mM}$ for phenol) of the respective toxicants were added to each 20 $\mathrm{ml}$ screw capped glass test tube to obtain the different binary mixture ratios or different concentrations of individual toxicants. Thereafter, $0.2 \mathrm{ml}$ each of $0.1 \% \mathrm{w} / \mathrm{v}$ solution of TTC and yeast suspension was added into each tube. The final concentration of toxicants ranged from 0 to $5 \mathrm{mM}$ for zinc, 0 to $16 \mathrm{mM}$ for phenol and 0 to $0.4 \mathrm{mM}$ for cadmium as individual chemical. Binary mixtures of zinc and cadmium ranged from 0 to $5.0 \mathrm{mM}$, phenol and zinc ranged from 0 to $16 \mathrm{mM}$. The controls consist of the medium without the toxicants. The cultures were incubated at room temperature $\left(28^{\circ} \mathrm{C} \pm 2^{\circ} \mathrm{C}\right)$ for $24 \mathrm{~h}$. After incubation, the formazan produced was extracted with $1 \mathrm{ml}$ of $1 \% \mathrm{v} / \mathrm{v}$ triton $\mathrm{x} 100$ and $4 \mathrm{ml}$ of butanol. Absorbance of the extract was determined spectrophotometrically at $500 \mathrm{~nm}$.

\subsection{Estimation of Response}

The inhibition of dehydrogenase activity at varying concentrations of the individual component and binary mixtures of phenol, cadmium and zinc were calculated as indicated in Equation below [18]. The inhibition (\%) was generated as mean and standard deviation from triplicate determinations.

$$
\% \mathrm{INH}=\frac{C_{A}-T_{A}}{C_{A}} \times 100
$$

where: $C_{A}$ is the absorbance of TPF extract in the control.

$T_{A}$ is the absorbance of TPF extract in the test with different concentrations of the toxicants as single, binary and ternary mixtures.

\subsection{Determination of Toxicity Threshold}

The dose response data from the assessment of toxic effects of the toxicants in their binary mixtures on dehydrogenase activities of the yeast were tested with 3-parameter logistic model (Equation below) [19] to obtain their respective toxicity threshold $\left(\mathrm{IC}_{50}\right)$ which is defined as the concentrations of the toxicants that inhibited the dehydrogenase activity of the yeast by $50 \%$.

$$
\% \mathrm{INH}=\frac{100}{1+\left(\frac{x}{\mathrm{IC}_{50}}\right)^{b}}
$$

where: $x$ is the concentration of the toxicant, $\mathrm{IC}_{50}$ is the concentration that caused 50\% inhibition; $b$ is parameter determining the relative slope at $\mathrm{IC}_{50}$.

In order to predict hormesis, i.e. stimulation of enzyme activity at low concentration of individual toxicant or the mixtures, the dose-response data were fitted to hormetic model equation stated below [20]. 


$$
\operatorname{Inhibition}(\%)=100-\frac{100-f x}{1+\left[1+\left\{\frac{2 \mathrm{FIC}_{50}}{100}\right\}\right]\left(\frac{x}{\mathrm{IC}_{50}}\right)^{b}}
$$

where: $f$ is the parameter describing the degree of hermetic response.

\subsection{Determination of Toxic Index (TI)}

Toxic index (TI) model was used to analyze the combined effect of the mixtures. The TI values were calculated using the expression:

$$
\mathrm{TI}=\sum_{i=1}^{n} \mathrm{TU}_{i}
$$

TU $i$ is the toxic unit of $i$ th component in the mixture. Each toxic unit was computed using the expression

$$
\mathrm{TU}_{i}=\frac{C \operatorname{mix}_{i}}{\mathrm{IC}_{50 i}}
$$

where: $C \operatorname{mix}_{i}$ is the concentration of the $i$ th toxicant in the mixture and $\mathrm{IC}_{50 i}$ is the $\mathrm{IC}_{50}$ of the same toxicant when tested as an individual. $\mathrm{TI}=1 \mathrm{describes}$ additivite interation, TI $>1$ describes antagonistic interaction and TI $<1$ describes synergistic interaction [21].

\section{Results}

The physicochemical properties and microbial load of the soil sample are as shown in Table 1.

Table 1. Physicochemical properties and microbial load of the soil sample.

\begin{tabular}{cc}
\hline Parameter/unit & Value \\
\hline $\mathrm{pH}$ & 6.88 \\
Phosphate $(\mathrm{mg} / \mathrm{kg})$ & 18.64 \\
Potassium $(\mathrm{cmol} / \mathrm{kg})$ & 0.076 \\
Calcium $(\mathrm{cmol} / \mathrm{kg})$ & 0.986 \\
Magnesium $(\mathrm{cmol} / \mathrm{kg})$ & 0.372 \\
Copper $(\mathrm{kg})$ & 0.50 \\
Zinc $(\mathrm{kg})$ & 1.56 \\
Lead $(\mathrm{kg})$ & 8.90 \\
Cadmium $(\mathrm{kg})$ & 3.70 \\
Total hydrocarbon content $(\%)$ & 0.465 \\
Total organic carbon content $(\%)$ & 1.246 \\
Total organic matter content $(\%)$ & 2.148 \\
Total nitrate content $(\%)$ & 0.120 \\
Medium & Microbial load (CFU/g) \\
PDA + Streptomycin $(50 \mu \mathrm{g} / \mathrm{ml})$ & $0.6 \times 10^{-5}$ \\
NA + Ketoconazole $(50 \mu \mathrm{mg} / \mathrm{ml})$ & $1.6 \times 10^{-5}$ \\
NA & $3.3 \times 10^{-6}$ \\
\hline
\end{tabular}

Key: PDA = Potato Dextrose Agar, NA = Nutrient Agar. 


\subsection{Toxicity of Single Chemicals}

The responses of the Cryptococcus $s p$. and Saprochaete $s p$. to the toxicity of zinc, phenol and cadmium as individuals are shown in Figure 1. Phenol presented biphasic dose response curves characterized by stimulation of dehydrogenase activity at low doses and inhibition at high doses. Hormesis (stimulatory) occurred at concentrations up to $2.0 \mathrm{mM}$ phenol for both yeasts. At concentrations above the stimulatory levels, phenol increasingly inhibited dehydrogenase activity as the concentration increased. Cadmium exhibited sharp inhibitory effect as the concentration increases while zinc showed a progressive inhibition of the dehydrogenase activity of both yeasts as the concentration increases.

\subsection{Toxicity of Binary Mixtures of Chemicals}

Toxicity of binary mixtures of the chemicals is shown in Figures 2-6. The binary mixtures of zinc and phenol were found to be stimulatory to the dehydrogenase activity at low doses and inhibitory at high doses. This Hormetic effect was higher with zinc and phenol mixtures ratios of 5.9\%Zinc + 94.1\%Phenol and $20 \%$ Zinc $+80 \%$ phenol respectively; it showed stimulatory effects at low concentrations for dehydrogenase activity of Saprochaete sp. While Cryptococcus sp. did not exhibit hermetic effect for zinc and phenol. Above the hermetic concentration range, the chemicals inhibited the dehydrogenase activities of the yeasts. The binary mixtures of zinc and cadmium show progressive inhibitory effects on the dehydrogenase enzyme activity of the both yeasts as the concentration increases.

\subsection{Toxicity Threshold ( $\left.\mathrm{IC}_{50}\right)$}

The toxicity threshold for the single and binary mixtures of the chemicals on both Saprochaete sp. and Cryptococcus sp., are shown in Table 2. For the single chemicals, Cadmium has an $\mathrm{IC}_{50}$ value of $(0.075 \pm 0.012) \mathrm{mM}$ for Saprochaete $s p$. and $(0.09 \pm 0.005) \mathrm{mM}$ for Cryptococcus $s p$. This shows that cadmium had higher toxic effect on the yeasts than zinc and phenol with $(0.385 \pm 0.012) \mathrm{mM}$, $(0.358 \pm 0.025) \mathrm{mM}$ and $(6.110 \pm 0.217) \mathrm{mM},(6.489 \pm 0.387) \mathrm{mM}$ respectively. For the binary mixtures of zinc and phenol, mixture ratio of $50 \% \mathrm{Znic}+$ $50 \%$ Phenol had the highest toxicity with $\mathrm{IC}_{50}$ value of $(1.022 \pm 0.085) \mathrm{mM}$ for Saprochaete $s p$., and mixture ratio of $27.3 \% \mathrm{Zinc}+72.7 \%$ Phenol had the highest toxicity with $\mathrm{IC}_{50}$ value of $(0.844 \pm 0.042) \mathrm{mM}$ for Cryptococcus $s p$., mixture ratio of $5.9 \%$ Zinc $+94.1 \%$ Phenol had lowest toxicity on Saprochaete $s p$. with $\mathrm{IC}_{50}$ of $(2.255 \pm 0.064) \mathrm{mM}$ and $(1.505 \pm 0.077) \mathrm{mM}$ for Cryptococcus sp. with the same mixture ratio. Mixture ratios of $88.8 \%$ Zinc $+11.2 \%$ Cadmium gave the highest toxicity for Saprochaete $s p$. with $\mathrm{IC}_{50}$ of $(0.185 \pm 0.022) \mathrm{mM}$ while mixtures ratios of $75 \%$ Zinc $+25 \%$ Cadmium gave the highest toxicity for Cryptococcus sp. with $\mathrm{IC}_{50}$ of $(0.276 \pm 0.052) \mathrm{mM}$.

\subsection{Toxic Interaction}

Toxic interactions of the binary mixtures of the chemicals on the yeast strains 
are shown in Table 3. For binary mixtures of zinc and phenol, all the mixtures ratios evaluated showed antagonistic interaction expect 5.9\%Zinc $+94.1 \%$ Phenol which shows synergistic effect for Saprochaete $s p$, while for Cryptococcus $s p$, all the mixtures ratios showed synergistic interaction with the exception of 50\%Zinc $+50 \%$ Phenol, which show antagonistic interaction. For the binary mixtures of zinc and cadmium, all the mixtures ratios showed antagonistic interaction with the exception of $88.8 \%$ Zinc $+11.2 \%$ Cadmium, which exhibited synergistic effect for Saprochaete $s p$, while for Cryptococcus $s p$, all the mixtures ratios exhibited antagonistic interaction.

Table 2. Toxicity thresholds $\left(\mathrm{IC}_{50}\right)$ of chemicals as single and binary mixtures on dehydrogenase activity of the test yeasts.

\begin{tabular}{ccc}
\hline & \multicolumn{2}{c}{$\mathrm{IC}_{50}(\mathrm{mM})$} \\
\hline Single & Saprochaete sp. & Cryptococcus sp. \\
Zinc & & \\
Phenol & $0.385 \pm 0.012$ & $0.358 \pm 0.025$ \\
Cadmium & $6.11 \pm 0.217$ & $6.489 \pm 0.387$ \\
Binary & $0.075 \pm 0.012$ & $0.09 \pm 0.005$ \\
Zinc/phenol & & \\
$5.9 \%$ Zinc + 94.1\%Phenol & $2.255 \pm 0.064$ & $1.505 \pm 0.077$ \\
20\%Zinc + 80\%Phenol & $1.937 \pm 0.083$ & $0.906 \pm 0.051$ \\
27.3\%Zinc + 72.7\%Phenol & $1.554 \pm 0.064$ & $0.844 \pm 0.042$ \\
$50 \%$ Zinc + 50\%Phenol & $1.022 \pm 0.085$ & $1.355 \pm 0.195$ \\
Zinc/Cadmium & & \\
66.6\%Zinc + 33.3\%Cadmium & $0.638 \pm 0.113$ & $0.404 \pm 0.031$ \\
88.8\%Zinc + 11.2\%Cadmium & $0.185 \pm 0.022$ & $0.280 \pm 0.007$ \\
92.3\%Zinc + 7.7\%Cadmium & $0.403 \pm 0.024$ & $0.445 \pm 0.124$ \\
$75 \%$ Zinc + 25\%Cadmium & $0.307 \pm 0.0132$ & $0.276 \pm 0.052$ \\
\hline
\end{tabular}

Table 3. Toxic Interactions of the binary mixtures of the test chemicals on the yeasts.

\begin{tabular}{ccccc}
\hline \multirow{2}{*}{ Mixture/Ratio } & \multicolumn{2}{c}{ Saprochaete sp. } & \multicolumn{2}{c}{ Cryptococcus sp. } \\
\cline { 2 - 5 } & Toxic Index (TI) & Interaction & Toxic Index (TI) & Interaction \\
\hline 66.6\%Zinc + 33.3\%Cadmium & 3.938 & Antagonistic & 2.248 & Antagonistic \\
88.8\%Zinc + 11.2\%Cadmium & 0.703 & Synergistic & 1.043 & Antagonistic \\
92.3\%Zinc + 7.7\%Cadmium & 1.380 & Antagonistic & 1.528 & Antagonistic \\
75\%Zinc + 25\%Cadmium & 1.621 & Antagonistic & 1.345 & Antagonistic \\
5.9\%Zinc + 94.1\%Phenol & 0.693 & Synergistic & 0.466 & Synergistic \\
20\%Zinc + 80\%Phenol & 1.343 & Antagonistic & 0.618 & Synergistic \\
27.3\%Zinc + 72.7\%Phenol & 1.512 & Antagonistic & 0.731 & Synergistic \\
50\%Zinc + 50\%Phenol & 1.411 & Antagonistic & 1.997 & Antagonistic \\
\hline
\end{tabular}




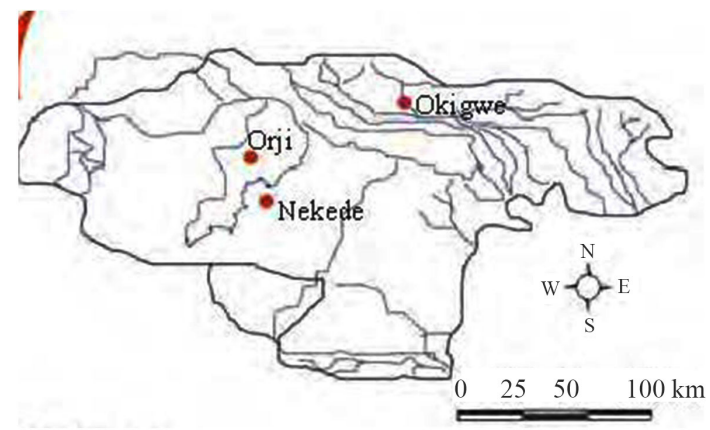

Figure 1. Map of Imo state and the study area [22].
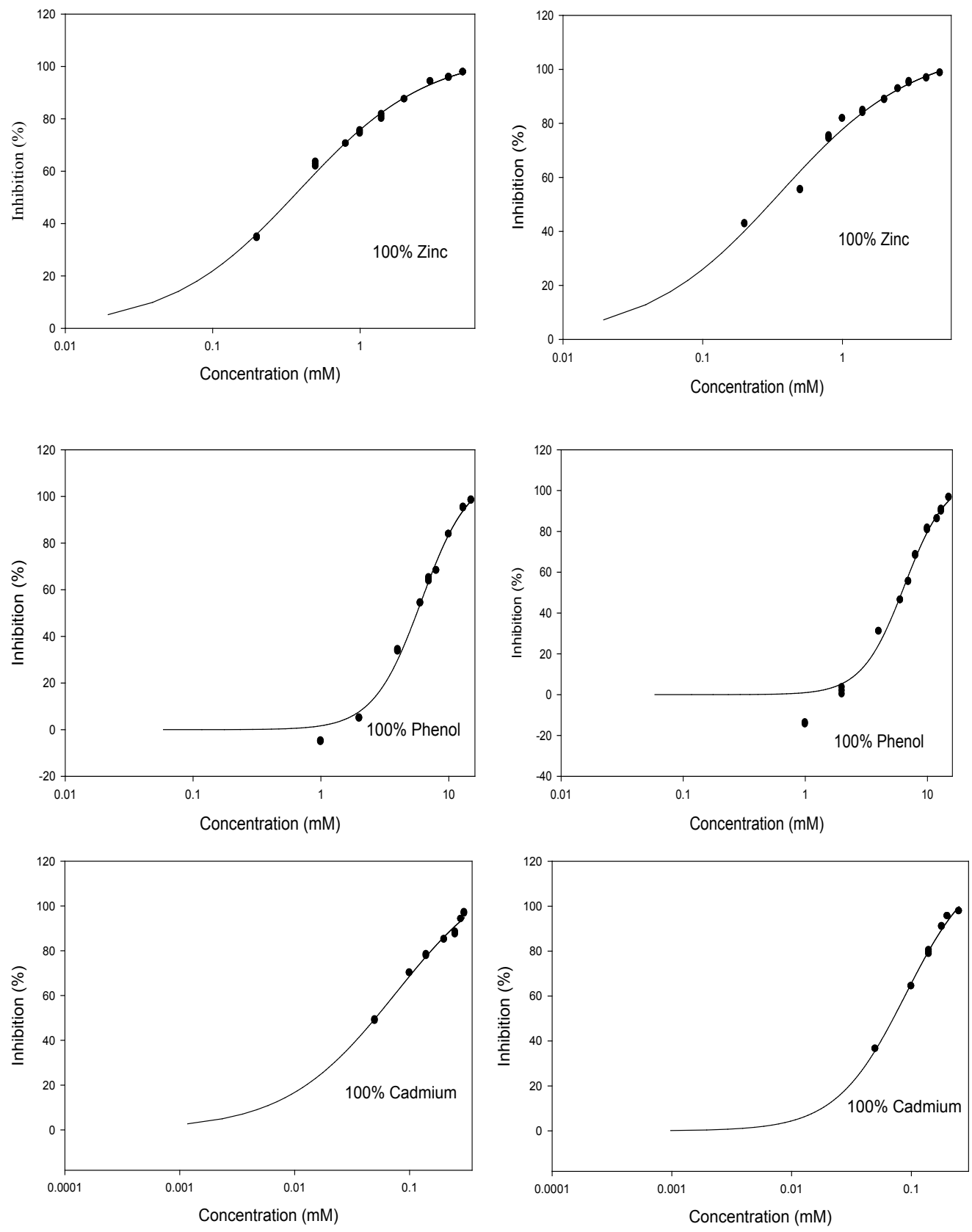

Figure 2. Toxicity of the single chemicals Zinc, phenol and Cadmium on yeast strains. 

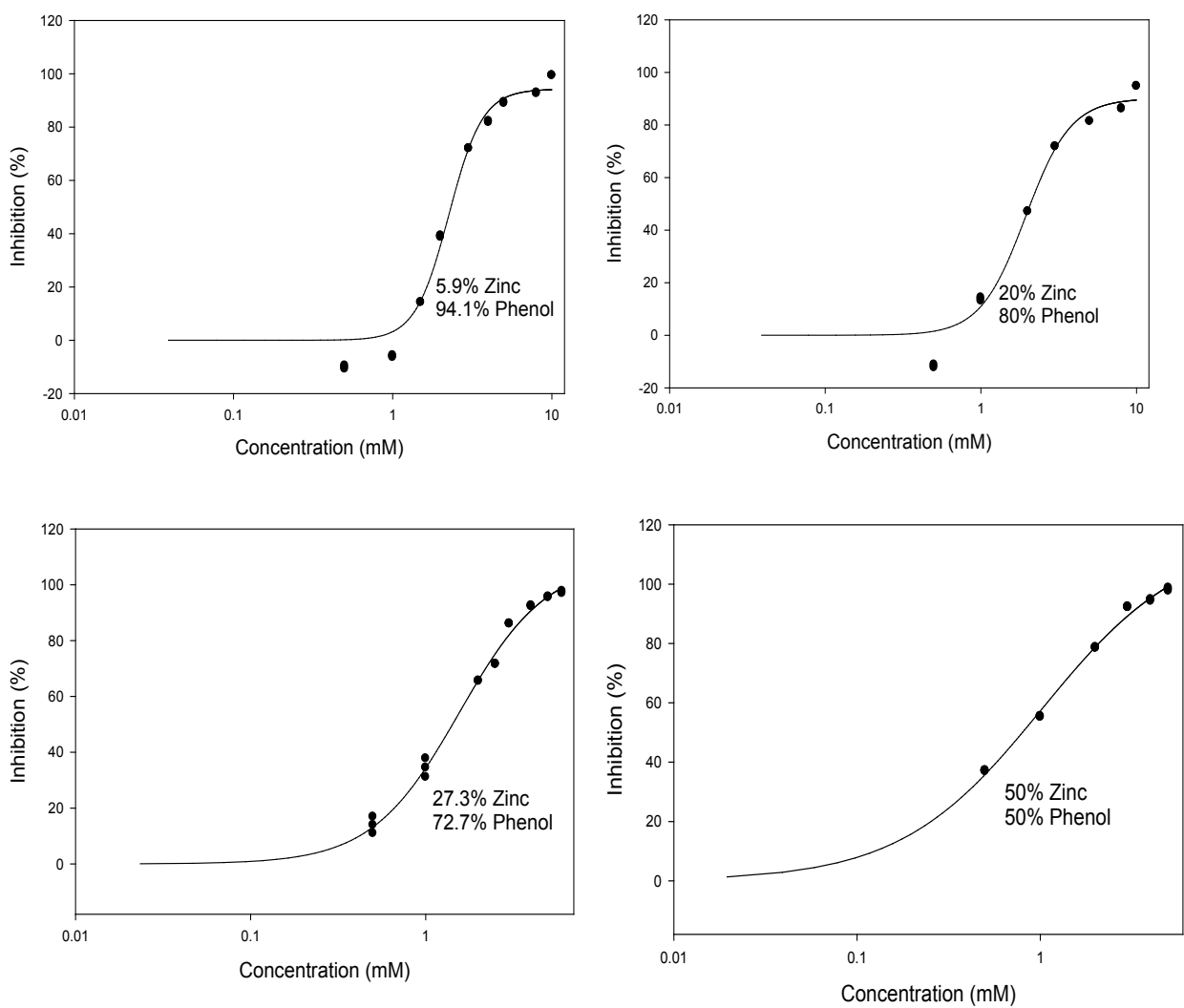

Figure 3. Toxicity of binary mixtures of Zinc and Phenol on Saprochaete sp.
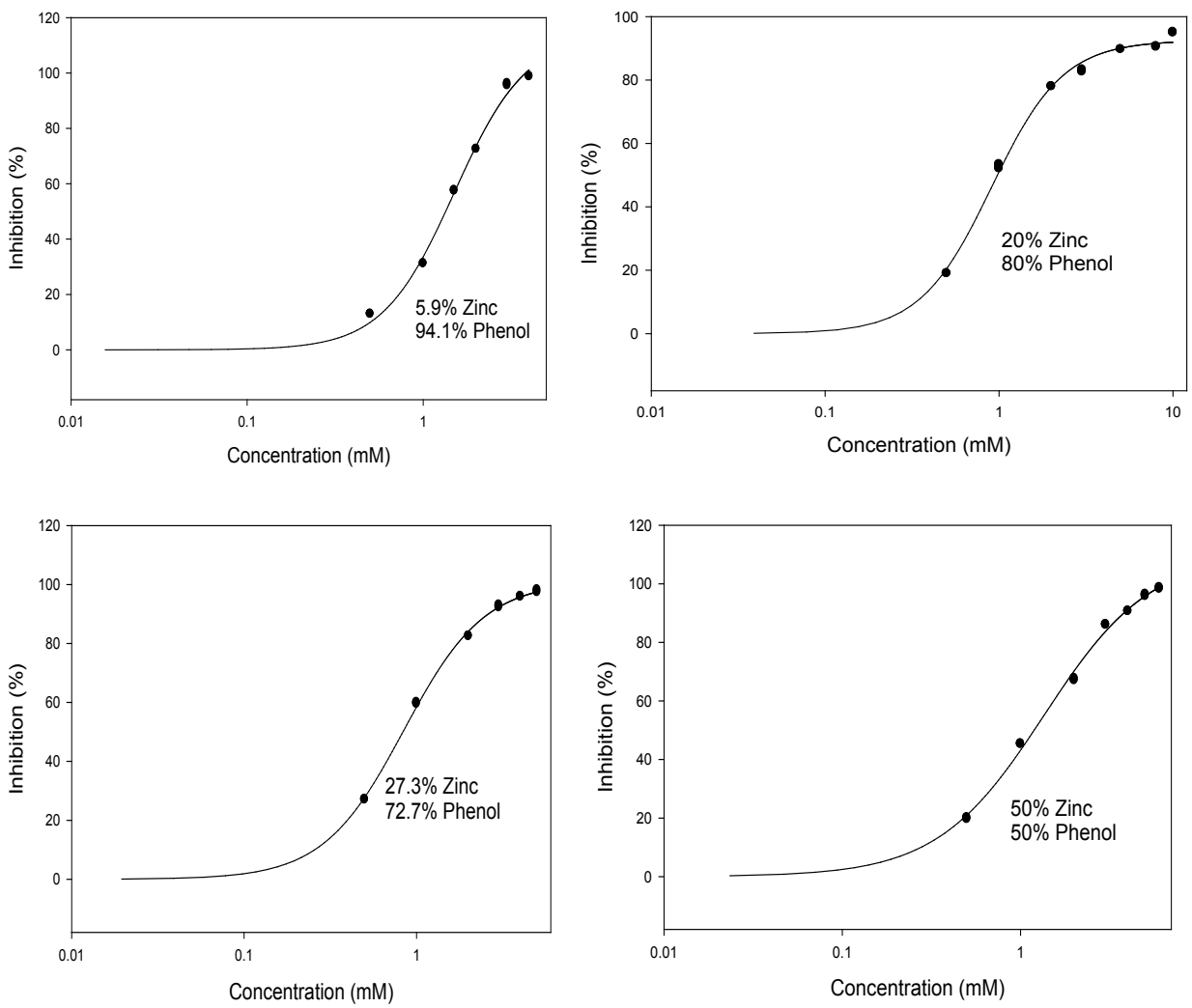

Figure 4. Toxicity of binary mixtures of Zinc and Phenol on Cryptococcus sp. 

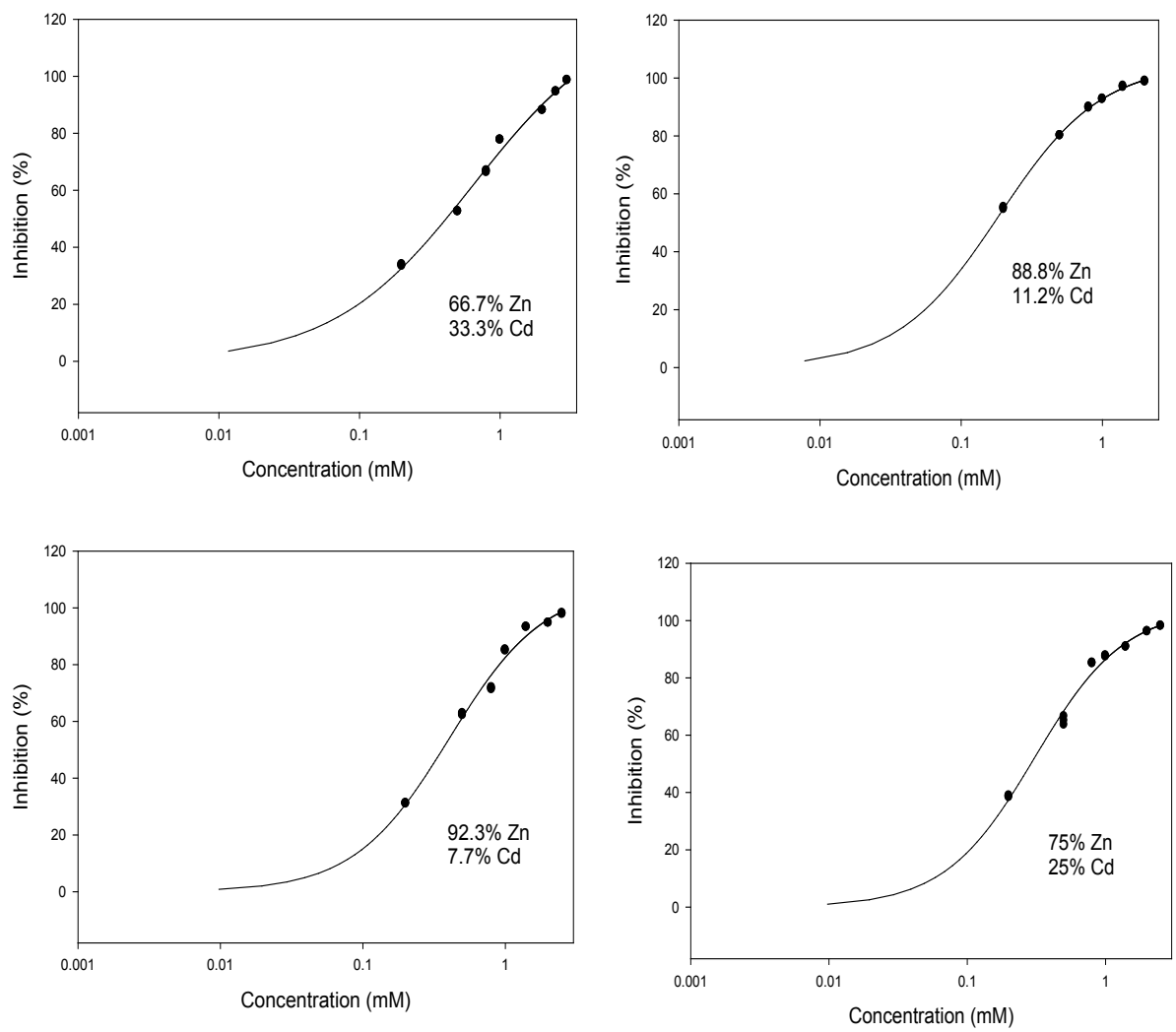

Figure 5. Toxicity of binary mixtures of Zinc and Cadmium on Saprochaete sp.
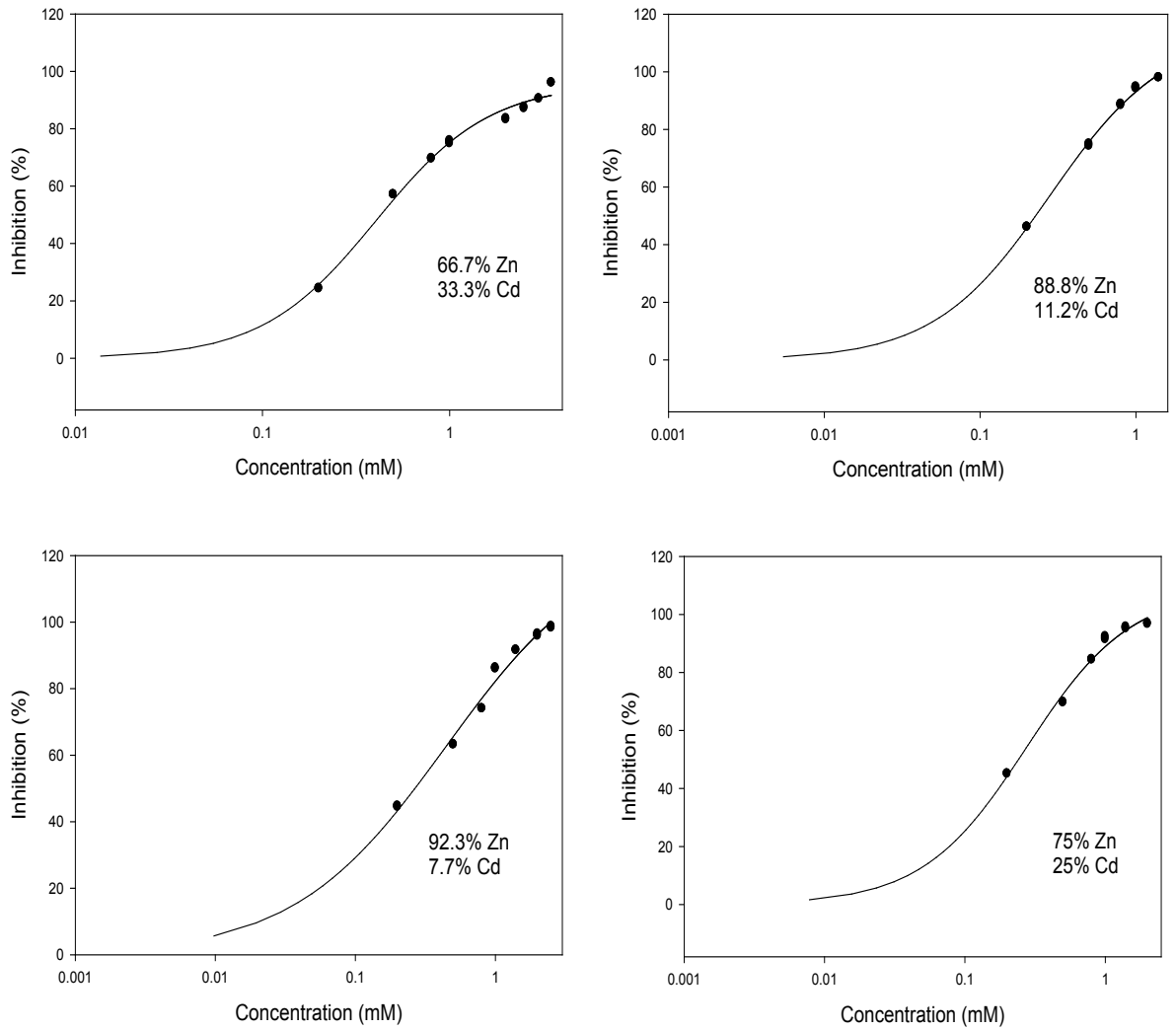

Figure 6. Toxicity of binary mixtures of Zinc and Cadmium on Cryptococcus sp. 


\section{Discussion}

This study investigated the individual and binary mixtures of chemicals (Zinc, Cadmium and Phenol) on yeast strains of Cryptococcus sp. and Saprochaete sp. In addition, Toxic Index model was also applied on the data to ascertain the possible interactions of the toxic chemicals.

Phenols are membrane damaging biocides [23], causing loss of cytoplasmic membrane integrity and thus disruption of membrane functions. Since dehydrogenases are membrane associated, loss of membrane integrity will ultimately affect their functions. The toxicity of the individual chemicals phenol, zinc and cadmium on dehydrogenase activity of both Saprochaete sp. and Cryptococcus $s p$. indicates progressive inhibition of the dehydrogenase activity of both yeasts as the concentrations of the chemicals increases. This is in line with the report of Nwanyanwu et al. [24], where increase in the concentrations of zinc, cadmium and phenolic conmpounds progressively inhibited the dehydrogenase activity of bacterial consortium. Cadmium exhibited sharp inhibitory effect on the dehydrogenase enzyme activities of the yeasts. This is in corroboration with the report of Nweke and Okpokwasili [25], where increase in phenol concentration decreases the dehydrogenase activity in the microbial community in refinery wastewater bacteria.

The dehydrogenase enzyme activity exhibited hormetic response upon exposure to heavy metals and phenolic compounds. Hormetic response to chemicals is a widely reported phenomena occurring in microorganisms and higher life [26]. The observed low dose stimulation (hormesis) in this study is in line with reported hormetic effect of metals and phenolic compounds. Nweke et al. [16] reported low dose stimulation of dehydrogenase activity of Rhizobium species by glyphosate, 4-chlorophenol and 2,4-dichlorophenol. They also reported that glyphosate, phenol, 4-CP and 2, 4-DCP progressively inhibited dehydrogenase activity [27]. In a study on the removal of phenol and zinc by Candida isolated from wastewater for integrated biological treatment, Mahgoub et al. [23] reported low dose stimulatory effect of zinc and phenol on Candida sp.

Certain metals such as copper, cobalt, nickel, iron and zinc are essential for normal growth and metabolism. Zinc, copper, chromium and iron may influence the stability of the double helix of DNA while forming hydrogen bonds. However, in excess of physiologically required levels, these metals become toxic and disrupt the biochemical activities of cells. The toxicity of zinc ion observed in this study thus corroborated reported toxic effects of metal ions. Zinc is known to be a potent inhibitor of the respiratory electron transport systems in bacteria and eukaryotic organisms [28].

The response of Saprochaete sp. and Cryptococcus sp. to zinc toxicity in this study is similar to the report of Nweke [11]. Mahgoub et al. [23] reported high dose inhibitory effect of zinc ion on Candida sp.

Toxic index was applied on the data to explore the possible mechanism of the interactions of the chemicals. The chemicals in the mixtures produced synergis- 
tic, additive and antagonistic effect. Antagonistic effect of zinc and cadmium recorded in this study presumes that zinc may reduce the toxicity of cadmium on dehydrogenase enzyme activity. Antagonistic interaction was observed by toxicity of zinc and cadmium binary mixtures on sea urchin embryo while addictive interaction was observe in quaternary mixtures of copper, lead, zinc and cadmium [25]. In this study, the order of toxicity Zinc $>$ phenol is in line what is reported by Nweke et al. [20]. The order toxicity is Cadmium $>$ Zinc $>$ Phenol.

\section{Conclusion}

The aim of the study was to assess the toxicity of phenol, zinc and cadmium in their single and binary mixtures on dehydrogenase activity of Saprochaete $s p$. and Cryptococcus sp. Cadmium exhibited more toxic effect than zinc and phenol. However, at low doses, phenol showed stimulatory effect on the enzyme activity of both yeast strains. The response of the enzyme activity to binary mixtures suggests that zinc and cadmium mixtures exhibited high toxicity. Toxic Index analysis showed that in most of the binary combinations, the interactions were synergistic and antagonistic. This information constitutes an essential contribution and serves as benchmark towards assessing the environmental risk of heavy metals and phenol especially as possible co-contamination of agricultural and aquatic environment. This study needs to be extended to microbial communities of soil or aquatic ecosystems, since microbes exist as a consortium rather than pure cultures in natural environments.

\section{Conflicts of Interest}

The authors declare no conflicts of interest regarding the publication of this paper.

\section{References}

[1] Teixeira, L.A.C., Nildo de Abreu, V.J., Lidia, Y. and Fabiana, V. (2015) Degradation of Phenol in Mine Waters Using Hydrogen Peroxide and Commercial Steel Wool. International Journal of Mineral Processing, 138, 15-19. https://doi.org/10.1016/j.minpro.2015.03.006

[2] Wang, D., Zhong, W. and Xu, X. (2012) Phenol Removal Efficiencies of Sewage Treatment Processes and Ecological Risks Associated with Phenols in Effluents. Journal of Hazardous Materials, 217-218, 286-292. https://doi.org/10.1016/j.jhazmat.2012.03.026

[3] Cravotta, I.C.A. and Brady, K.B.C. (2015) Priority Pollutants and Associated Constituents in Untreated and Treated Discharges from Coal Mining or Processing Facilities in Pennsylvania, USA. Applied Geochemistry, 62, 108-130. https://doi.org/10.1016/j.apgeochem.2015.03.001

[4] Pishgar, R., Najafpour, G., Neya, B.N., Mousavi, N. and Bakhshi, Z. (2011) Anaerobic Biodegradation of Phenol: Comparative Study of Free and Immobilized Growth. Iranica Journal of Energy and Environment, 2, 348-355. https://doi.org/10.5829/idosi.ijee.2011.02.04.2361

[5] Salem, H.M., Eweida, E.A. and Farag, A. (2000) Heavy Metals in Drinking Water 
and Their Environmental Impact on Human Health. Proceedings of the International Conference for Environmental Hazards Mitigation, Giza, 9-12 September 2000, 542-556.

[6] Grąz, M., Pawlikowska-Pawlęga, B. and Jarosz-Wilkołazka, A. (2011) Growth Inhibition and Intracellular Distribution of Lead Ions by the White-Rot Fungus Abortiporus biennis. International Biodeterioration \& Biodegradation, 65, 124-129. https://doi.org/10.1016/j.ibiod.2010.08.010

[7] Blaudez, D., Botton, B. and Chalot, M. (2000) Cadmium Uptake and Subcellular Compartmentation in the Ectomycorrhizal Fungus Paxillus involutus. Microbiolo$g y$, 146, 1109-1117. https://doi.org/10.1099/00221287-146-5-1109

[8] Carrillo-Gonzalez, R. and Gonzalez-Chavez, M.C. (2012) Tolerance to and Accumulation of Cadmium by the Mycelium of the Fungi Scleroderma citrinum and Pisolithus tinctorius. Biological Trace Element Research, 146, 388-395.

https://doi.org/10.1007/s12011-011-9267-7

[9] Jaeckel, P., Krauss, G.J. and Krauss, G. (2005) Cadmium and Zinc Response of the Fungi Heliscus lugdunensis and Verticillium cf. alboatrum Isolated from Highly Polluted Water. Science of the Total Environment, 346, 274-279.

https://doi.org/10.1016/j.scitotenv.2004.12.082

[10] Quilchano, C. and Maranon, T. (2002) Dehydrogenase Activity in Mediterranean Forest Soil. Biology and Fertility of Soils, 35, 102-107. https://doi.org/10.1007/s00374-002-0446-8

[11] Nweke, C.O. and Okpokwasili, G.C. (2010) Inhibition of Dehydrogenase Activity in Petroleum Refinery Wastewater Bacteria by Phenolic Compounds. Ambiente \& Agua, 5, 6-16. https://doi.org/10.4136/ambi-agua.115

[12] Preston, S., Coad, N., Townend, J., Killham, K. and Paton, G.I. (2000) Biosensing the Acute Toxicity of Metal Interactions: Are They Additive, Synergistic, or Antagonistic? Environmental Toxicology and Chemistry, 19, 775-780. https://doi.org/10.1002/etc.5620190332

[13] APHA (1985) Standard Methods for the Examination of Water and Wastewater. 16th Edition, American Public Health Association, American Water Works Association and Water Pollution Control Federation, Washington DC.

[14] Walker-Black, I.A. (1934) An Examination of the Degtjareff Method for Soil Organic Matter Determination and a Proposed Modification, of the Chronic Acid Titration. Soil Science, 37, 29-38. https://doi.org/10.1097/00010694-193401000-00003

[15] Juo, A.S.R. (1979) Selected Methods for Soil and Plant Analysis. Manual Series No. 1, IITA, Ibadan.

[16] Nweke, C.O., Ahumibe, N.C. and Orji, J.C. (2014) Toxicity of Binary Mixtures of Formulated Glyphosate and Phenols to Rhizobium Species Dehydrogenase Activity. Journal of Microbiology Research, 4, 161-169.

[17] Campbell, C.K., Johnson, E.M. and Warnock, D.W. (2013) Identification of Pathogenic Fungi. 2nd Edition, Blackwell Publishing Ltd., West Sussex, 263-304. https://doi.org/10.1002/9781118520055

[18] Nwachukwu, M.A., Huan, F. and Kennedy, A. (2010) Integrated Study for Automobile Wastes Management and Environmentally Friendly Mechanic Villages in the Imo River, Basin, Nigeria. African Journal of Environmental Science and Technology, 4, 234-249.

[19] Schabenberger, O., Tharp, B.E., Kells, J.J. and Penner, D. (1999) Statistical Test for Hormesis and Effective Dosages in Herbicide Dose-Response. Agronomy Journal, 91, 713-721. https://doi.org/10.2134/agronj1999.914713x 
[20] Boillot, C. and Perrodin, Y. (2008) Joint-Action Ecotoxicity of Binary Mixtures of Glutaraldehyde and Surfactants Used in Hospitals: Use of the Toxicity Index Model and Isobologram Representation. Ecotoxicology and Environmental Safety, 71, 252-259. https://doi.org/10.1016/j.ecoenv.2007.08.010

[21] Okolo, J.C., Nweke, C.O., Nwabueze, R.N., Dike, C.U. and Nwanyanwu, C.E. (2007) Toxicity of Phenolic Compounds to Oxidoreductases of Acinetobacter Species Isolated from a Tropical Soil. Scientific Research Essay, 2, 244-250.

[22] Nweke, C.O., Ike, C.C. and Ibegbulem, C.O. (2016) Toxicity of Quaternary Mixtures of Phenolic Compounds and Formulated Glyphosate to Microbial Community of River Water. Ecotoxicology and Environmental Contamination, 11, 63-71. https://doi.org/10.5132/eec.2016.01.09

[23] Mahgoub, S., Abdelbasit, H. and Abdeifattah, H. (2015) Removal of Phenol and Zinc by Candida Isolated from Wastewater for Integrated Biological Treatment. Desalination and Water Treatment, 53, 3381-3387. https://doi.org/10.1080/19443994.2014.934113

[24] Nwanyanwu, C.E., Adieze, I.E., Nweke, C.O. and Nzeh, B.C. (2017) Combined Effects of Metals and Chlorophenols on Dehydrogenase Activity of Bacterial Consortium. International Research Journal of Biological Sciences, 6, 10-20.

[25] Nweke, C.O. and Okpokwasili, G.C. (2010) Influence of Exposure Time on Phenol Toxicity to Refinery Wastewater Bacteria. Journal of Environmental Chemistry and Ecotoxicology, 2, 20-27.

[26] Choudhury, R. and Srivastava, S. (2001) Zinc Resistance Mechanisms in Bacteria. Current Science, 81, 768-775.

[27] Xu, X., Li, Y., Wang, Y. and Wang, Y. (2011) Assessment of Toxic Interactions of Heavy Metals in Multi-Components Mixtures Using Sea Urchin Embryo-Larval Bioassay. Toxicology in Vitro, 25, 294-230. https://doi.org/10.1016/j.tiv.2010.09.007

[28] Calabrese, E.J. and Blain, R. (2005) The Occurrence of Hormetic Dose Responses in the Toxicological Literature, the Hormesis Database: An Overview. Toxicology and Applied Pharmacology, 202, 289-301. https://doi.org/10.1016/j.taap.2004.06.023 